\title{
RUEDA SUELTA ENTRE LOS NAZIS: LA AVERSIÓN TEÓRICA DE CARL SCHMITT FRENTE AL NAZISMO*
}

Guillermo Andrés Duque Silva**

Fecha de recepción: 2 de diciembre de 2014

Fecha de evaluación: 28 de marzo de 2015

Fecha de aprobación: 18 de agosto de 2015

Artículo de reflexión

DOI: http://dx.doi.org/10.18359/prole.1681

Forma de citación: Duque, G. (2016). Rueda suelta entre los nazis: la aversión teórica de Carl Schmitt frente al nazismo. Revista Prolegómenos Derechos y Valores, 19, 37, 85-98. DOI: http://dx.doi.org/10.18359/prole.1681

\section{Resumen}

El interés por Carl Schmitt en los primeros años del siglo XXI se hace cada vez más evidente, especialmente en autores que buscan renovar la tradición liberal apelando a los argumentos de este polémico autor. Pese al lugar común que significa Schmitt, su reconocimiento general viene acompañado de una suerte de estigmatización difícil de superar, con la que en ocasiones se le califica de "cómplice" de la tragedia del nazismo. En este artículo se presenta una reflexión en torno a la comprensión que tenía Carl Schmitt sobre el derecho. En dicho análisis se emplea un método hermenéutico de estudio de la primera obra de Schmitt; su tesis de habilitación de 1914. El artículo permite ver que muchos de los elementos de la filosofía política schmittiana en su conjunto, se definen en esta primera obra, la que ideológicamente se ajusta mejor al pensamiento burgués-conservador que a los fundamentos del nazismo.

\section{Palabras clave:}

Carl Schmitt, decisionismo, teología política, soberano, Estado de excepción.

\section{LOOSE WHEEL AMONG NAZIS: THE THEORETICAL AVERSION OF CARL SCHMITT BEFORE NAZISM}

\section{Summary}

The interest of Carl Schmitt in the first years of XXI century becomes increasingly evident, especially in authors who try to renew the liberal tradition appealing to the arguments of this

" Artículo resultado de la investigación "El rescate de lo político: Carl Schmitt en la discusión filosófica contemporánea" adscrita al Grupo de Investigación Praxis Política de la Universidad del Valle, Cali, Colombia, finalizada en junio de 2013 y dirigida por el profesor Delfín Ignacio Grueso, Ph.D.

* Investigador principal. Licenciado en Historia de la Universidad del Valle. Especialista en Gerencia de Instituciones Educativas de la Universidad del Tolima, Ibagué, Colombia. Magíster en Filosofía de la Universidad del Valle. Miembro del Grupo de Investigación Praxis Política de la misma institución. Becario Colciencias en Departamento de Filosofía de la Universidad del Valle. Líder del Grupo de Investigación Solidarios de la Facultad de Derecho de la Universidad Cooperativa de Colombia. Director de investigaciones de la Universidad Cooperativa de Colombia, sede Cali. Correo electrónico: guillermo.duque@ucc.edu.co 
polemical author. Despite the common place that Schmitt means, his general acknowledgement comes along with a kind of stigmatization difficult to overcome, with which he is sometimes classified as "accomplice" of the Nazism tragedy. In this article a reflexion is presented around the comprehension that Carl Schmitt had about law. In such analysis, a hermeneutic method of study of Schmitt's first work is used: his habilitation thesis in 1914. The article lets us see that many of the elements of the Schmitt's political philosophy in total are defined in this first work, which ideologically fits to the bourgeois-conservator knowledge better than to the Nazism fundamentals.

\section{Keywords:}

Carl Schmitt, decision party, political theology, sovereignty, state of emergency.

\section{ELO FRACO ENTRE OS NAZISTAS: A AVERSÃO TEÓRICA DE CARL SCHMITT PERANTE O NAZISMO}

\section{Resumo}

O interesse por Carl Schmitt nos primeiros anos do século XXI está cada vez mais evidente, especialmente entre autores que buscam renovar a tradição liberal apelando aos argumentos deste polemico autor. Apesar do lugar comum em que se encontra Schmitt, seu reconhecimento vem acompanhado de uma espécie de estigmatizarão difícil de superar ao ser tachado como "cúmplice" da tragédia que foi o nazismo. Neste artigo pretendemos apresentar uma reflexão em torno da compreensão que teria Carl Schmitt sobre o direito. Nesta análise aplica-se um método hermenêutico de estudo da primeira obra de Schmitt; a sua tese de habilitação escrita em 1914. O artigo permite visualizar variados elementos da filosofia política schmittiana em seu conteúdo e que são definidas na sua primeira obra, e que ideologicamente se ajusta melhor ao pensamento burgues-conservador, do que ao dos fundamentos nazista.

\section{Palavras-chave:}

Carl Schmitt, decisionismo, teologia política, soberano, Estado de exceção.

\section{Introducción}

Carl Schmitt ha estado al tiempo presente y ausente en el conjunto de la filosofía política contemporánea; aunque aportó una serie de conceptos límite para el desarrollo de la crítica al liberalismo, él mismo llega a constituirse en lo que se podría denominar un "filósofo límite": una referencia para muchos inevitable, más que necesaria ${ }^{1}$.

1 El recurso casi obligado a Schmitt en toda teoría política contemporánea crítica al liberalismo, representa el límite de un realismo que sirve como punto de referencia para
De nacionalidad alemana, se reconoció a sí mismo como jurista antes que como teórico político, aun cuando en sus textos otorgó una especial importancia a la política sobre el dere-

toda reflexión sobre lo político. Los postulados del alemán son la antítesis del argumento liberal predominante en la filosofía occidental y se utilizan tanto para atacar al liberalismo -por ejemplo: Álvaro d'Ors, (2002)- como para defenderlo contra-argumentativamente -por ejemplo: Paul W. Kahn (2012)-; de ahí que lo realmente cardinal en Schmitt, parece que es, más que su propuesta filosófica, lo que representa como referencia limítrofe de la argumentación filosófica liberal, republicana y marxista. 
cho. Carl Schmitt, considerado por muchos en su momento como el mejor lector de Hobbes y Maquiavelo, nació en Plettenberg en 1888 y murió el 7 de abril 1985 en la misma ciudad, luego de una larga etapa de viajes académicos a Estados Unidos, Italia, España y Francia. La fuerza de sus planteamientos logra inspirar simultáneamente a la extrema derecha y a la extrema izquierda, a través de obras como Romanticismo político (1919) y Teoría del partisano: acotación al concepto político (2013), respectivamente ${ }^{2}$.

Durante la década del veinte y del treinta, Schmitt mantuvo una crítica permanente a las instituciones y fundamentos democráticos de la República de Weimar, lo que condujo a una fructífera discusión con el ala legalista del liberalismo en particular $^{3}$, y en general con el individualismo apolítico subyacente a la democracia burguesa. Sobre este último punto, se destacan las dos obras de mayor difusión de Schmitt: un ensayo titulado "El concepto de lo político" (1991) y dos volúmenes de un escrito en el que condensa gran parte de sus postulados más elaborados, al que llamó Teología política (1998). La amplia lectura de ambas obras en Hispanoamérica y el hecho de que Schmitt abrió múltiples interrogantes respecto a los nexos entre sus planteamientos teóricos y el nazismo, han provocado que no sean pocos los intérpretes que le señalen como emblema del nazismo.

El año pasado, en 2014, el Centro de Estudios Políticos y Constitucionales de España, con la dirección de Celestino Pardo, reimprimió la tesis de habilitación de Carl Schmitt, titulada en español El valor del Estado y el significado del individuo, este texto empieza a generar revuelo por aclarar las profundas distancias teóricas entre los fundamentos filosóficos de Schmitt y los fundamentos ideológicos nazis.

2 Inclusive llega a generar entusiasmo en las facciones del antiimperialismo anglosajón con El nomos de la tierra en el derecho de gentes del "Ius publicum europaeum" (1943).

3 Discusión desarrollada principalmente con Hans Kelsen en Teoría de la Constitución (1928), El guardián de la Constitución (1931) y Legalidad y legitimidad (1932).
Sobre este primer documento filosófico de Carl Schmitt se centrará la presentación y el análisis del pensamiento político de Schmitt, propuesto para este artículo. Ese texto representa la etapa juvenil del jurista alemán; una fase más teórica que práctica, donde reina una suerte de neoplatonismo que deja como resultado su propuesta teórica decisionista.

En ese "primer Carl Schmitt" no existe la vida pública, o al menos no es de su interés, los problemas que desea atender son los del origen del derecho y el Estado. La dicotomía normalidad/ excepción sobre la que asienta sus análisis, es la relación que da acceso al problema del soberano y la decisión en los Estados de excepción, aportes que van en dirección contraria al "dato" empírico que remite a Schmitt al nazismo. El objetivo de este artículo es, entonces, indagar en la primera etapa filosófica de Carl Schmitt, demostrando que su comprensión del derecho y el poder es propia de un modernismo burgués conservador, diametralmente opuesto a lo que luego se definirá como poder, derecho y movimiento en la ideología nacionalista y obrero-revolucionaria, del Partido Nazi.

Las razones que interpuso el nazismo a Schmitt para retirarlo del partido, tienen una profunda raíz teórica que se explica en la forma como el filósofo de Plettenberg entiende el derecho y la política, desde su primera obra, aspectos que no podría revaluar teóricamente, sin caer en flagrantes contradicciones.

En el acápite siguiente veremos porqué el valor del Estado en Schmitt es superior al de cualquier otra unidad política, por ejemplo el partido o el movimiento y porqué el catolicismo ocupa un lugar predilecto en la idea de orden concreto para este filósofo, contrario al concepto de Reich. La última parte del documento explica con datos históricos la tensa relación que mantuvo Carl Schmitt con el nazismo y la simpatía que guardaría con el fascismo italiano, ideología más acorde con sus postulados iniciales sobre el Estado, la política y el derecho. 


\section{A. El valor del Estado y su preemi- nencia sobre el movimiento en Carl Schmitt}

La primera etapa de Carl Schmitt es la de un fuerte crítico al proyecto moderno en clave liberal. A la manera de lo que hoy podríamos llamar un genealogista de lo moderno, el filósofo alemán indaga en el origen del Estado, el derecho y el poder para develar el momento caótico, irracional y violento que da origen a la modernidad. Esta idea se sugiere desde su primer libro filosófico: El valor del Estado y el significado del individuo, que es su tesis de habilitación de 1914. En esa obra, Schmitt plantea la idea de que el Estado, como forma política específica de la modernidad, es la expresión de la tragedia moderna.

Esta "tragedia", según él, se explica como el resultado de una desconexión, tan necesaria como perturbadora, entre idea y realidad. Categorías que, en palabras de un Schmitt más jurista que filósofo, corresponden con los conceptos de derecho y poder, en el mundo de la política. La primera noción de ese trabajo que será estructurante, consiste en que la trágica desconexión entre derecho y poder es el mito fundacional de la modernidad.

Según Schmitt las características del derecho, pensado en abstracto, son las del puro "deber ser" y reflejan el principio-del-orden-en-sí, por lo tanto se hallan completamente ajenas al mundo de los hechos, al mundo del poder. En consecuencia, ni el derecho es poder, ni el derecho surge del poder; $y$, sin embargo, hay una relación indisoluble entre ambos en la medida en que no hay poder establecido que no esté justificado jurídicamente. Por ende, y este es el sentido de su primer trabajo, aunque no todo derecho es poder, en todo poder hay derecho.

En otras palabras, Schmitt parte de la idea de que el derecho es un conjunto de normas abstractas, perfectas si se quiere, que está llamado a realización mediante el querer empírico de los hombres. Esta idea se concreta en una serie de argumentos que opone al constitucionalista Hans Kelsen en la discusión sobre la relación derecho-poder.

La distancia entre Kelsen y Schmitt se puede detallar en la manera como cada uno de ellos comprende el concepto de Estado de derecho. Para Kelsen, el Estado de derecho es primero "de derecho" y luego es "Estado", dado que en estricto rigor el Estado es tal, solamente a través del derecho (Fioravanti, 1994). Para Schmitt en cambio, no puede existir el derecho sino como resultado del principio de unidad política expresado en la Constitución y representado por el Estado (Fioravanti, 1994). Entonces, el derecho (la idea) y el poder (la realidad), forman parte de dos reinos desconectados uno del otro, que se encuentran en una mediación que permite que el derecho como mandato "sea-realizado", forzosamente, por el querer empírico de los hombres de realizar el derecho ${ }^{4}$.

Gráfica 1. El Estado y el derecho en Carl Schmitt

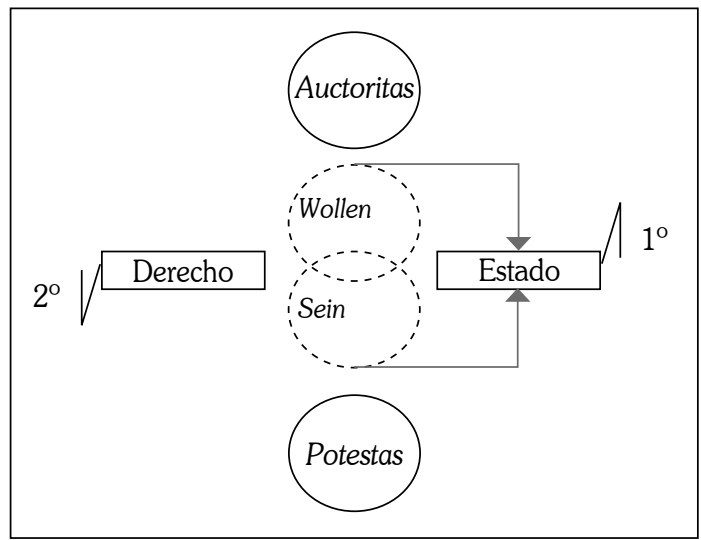

Fuente. Elaboración propia.

$4 \quad$ Esta explicación constituye una embestida contra el naciente positivismo jurídico kelseniano y la también incipiente perspectiva sociológica del derecho. En el fondo hay una reinterpretación de lo que Hobbes ya había reconocido como la distinción entre el principio de orden y cualquier orden concreto. Es curioso que en este documento Schmitt no cite a Hobbes. Una explicación para esto sería que el filósofo alemán se encuentra enfocado en un debate más jurídico que filosófico. 
Tal como se presenta en la gráfica 1, este primer Carl Schmitt plantea que el Estado moderno se justifica en la imposibilidad de pasar directamente de un orden normativo puro a la realidad de la vida social. Para este Schmitt, es una situación trágica de no correspondencia entre la voluntad de ser (wollen) y el ser (sein), lo que hace exigible la existencia del Estado moderno. Cualquier adecuación distinta a la hecha por la fuerza del Estado, es tan solo una falsificación del poder soberano. La idea inicial de "brecha trágica" entre derecho y poder, es perfeccionada por Schmitt en Teología política (1998), texto en el que el filósofo introduce el concepto de soberanía y lo equipara con el de Estado a partir del empleo de conceptos propios de la teología como el "milagro", la "revelación", la "muerte" y la "resurrección". Sin embargo para llegar a ese momento, primero hace un recorrido por el decisionismo weberiano y lo adapta a sus fines filosóficos.

\section{B. El catolicismo schmittiano: la decisión como milagro creador del derecho}

Si el Estado, tal y como lo ha definido hasta el momento Schmitt, es el ente administrador de la aporía entre derecho y poder, entonces él mismo es ante todo una acción que se ejecuta y esa acción es siempre una decisión por adecuar el derecho al poder, en la medida en que sugiere la elección por la orientación que tendrá el Estado en un momento posterior a la decisión. La decisión es, en consecuencia, el momento político por naturaleza.

El eje central del decisionismo como teoría, del cual Schmitt es uno de los principales exponentes, es "el nombre de una teoría comprometida con la decisión política" (Lübbe, 1983, p. 49). Aunque sea reconocido como padre del decisionismo jurídico, una aproximación a esta corriente teórica ya había sido aportada por Max Weber, quien sería un referente ejemplar para el mismo Schmitt.

Weber, quien como Schmitt tuvo la excepcional posibilidad de combinar la vida académica con la práctica de la política, afirmaría que la validez política de las normas, es decir, su validez social y su obligatoriedad legal, se genera en quienes detentan el poder, ya que no es posible que la fundamentación de las normas resulte de algún procedimiento estrictamente científico, del que además surja la decisión de obligar. Literalmente, el padre de la sociología admite que "no existe ningún método científico (racional o empírico), de cualquier tipo que este sea, que pueda ofrecer aquí una decisión" (Weber, 1979, p. 11).

Con esta frase, en realidad Weber no está desconociendo la fundamentación racional de la ley o de los fines de acción, lo que hace es una separación entre dos niveles: el nivel de la discusión y el nivel de la decisión, y la función que cada uno de estos tiene respecto a la obligación de la norma. Por supuesto, existen procedimientos susceptibles de diseñarse y ejecutarse científicamente para la fundamentación de las normas, pues

[...] es obvio que en nuestros Parlamentos, hasta los tribunales supremos de justicia $y$ los congresos de los partidos [...] se dedican continuamente y en diferentes instancias de la fundamentación de las normas, las leyes generales o los estatutos que en el ámbito de sus competencias, una vez que han sido acordados, han de valer para todos (Lübbe, 1983, p. 61).

Pues toda propuesta viene acompañada de una fundamentación lógica que le respalda. Sin embargo, "todo debate parlamentario, llega al momento en que ya no se sopesan argumentos, sino que se cuentan votos" (Lübbe, 1983, p. 62); esto es, se toman decisiones. La obligatoriedad de la norma que sucede al debate, no deriva de lo racional o bien argumentado que haya sido la discusión; su obligatoriedad se debe, finalmente, al resultado de la votación.

Sabemos que Weber optó por abordar el problema del orden político desde la perspectiva sociológica, indagando en las posibles instituciones que de una mejor forma podían ayudar a la toma de decisiones aceptables. Schmitt, por 
su parte, se pensó filosóficamente el instante en que se logra la mejor adecuación posible entre derecho y poder, entre idea y realidad. En esa reflexión surge su propuesta jurídica decisionista 5 .

El decisionismo schmittiano por ende, se edifica en la idea de que la decisión, sea una votación, la providencia de un magistrado o la sentencia de un juez, es la manifestación fenoménica de la soberanía, la existencia misma de la decisión es la prueba efectiva de la existencia de una dualidad irreconciliable: el hecho real, el caso, la sentencia y la existencia, por un lado, y el espíritu, la norma, la vida y la esencia, por el otro. Se puede decir entonces que en el decisionismo, más que una contraposición entre el deber ser (sollen) y ser (sein), hay una dicotomía entre voluntad (wollen) y ser (sein). El derecho que surge de la decisión, en consecuencia, es resultado de la interacción entre la voluntad que decide y la realidad en que está inserto quien decide. Esta relación del soberano con los "hechos" es primordial, pues estos últimos son los que finalmente terminan condicionando el contenido de la decisión (Schmitt, 2012).

Según Carl Schmitt, la razón y la voluntad, por un lado, la verdad y la autoridad, por el otro, son los únicos fundamentos posibles para un sistema jurídico unitario (Córdova, 2013), de manera que si la dicotomía ratio-veritas es el principio esencial del normativismo de corte iusnaturalista ${ }^{6}$,

5 Agnes Heller (2006) en su prólogo al libro El Leviatán en la doctrina del Estado de Thomas Hobbes de Carl Schmitt definió tres proposiciones fundamentales para el decisionismo de Schmitt, en las mismas se puede notar la distancia que Schmitt toma frente a Weber en los siguientes aspectos: (i) la decisión es el principal acontecimiento político, (ii) la soberanía descansa en el poder definitivo de la decisión y (iii) el poder de decisión acerca de y durante el estado de emergencia es la manifestación categórica de la soberanía. Para abordar el diálogo filosófico Weber-Schmitt, véase: Villacañas (2013, pp. 13-40).

6 Dado que "los principios de los cuales se derivan las normas jurídicas son el producto de una operación racional que los presupone al nacimiento del Estado y que los considera como válidos per se y por lo tanto, como característicos de una verdad (ya sea racional o absoluta)" (Córdova, 2013, p. 195). la dicotomía voluntas-auctoritas sería el cimiento de su teoría jurídica decisionista, dado que "la decisión es el producto de la "Voluntad' de quien está investido de la 'Autoridad' para emitirla" (Córdova, 2013, p. 195). En ese sentido, las decisiones fundan el derecho, en tanto que son generadas o responden a una voluntad general determinada y las toma un soberano investido de la autoridad necesaria para emitirlas.

La decisión opera en ese sentido como el milagro creador del derecho; la semejanza entre esta glosa del decisionismo y los conceptos aplicados a la teología para explicar la relación fe-razón, saltan a la vista. En efecto, Schmitt expone que la relación voluntas-rex-auctoritas es una proyección hacia la política secular, de los valores teológicos judeocristianos que caracterizan a Occidente como una sociedad construida en el dualismo (gnóstico) de "un Dios creador de este mundo lleno de maldad y un Dios salvador-amoroso y ajeno del mundo, mediante la unidad de padre e hijo" (Pardo, 2014, p. 30).

El objetivo primordial de Schmitt en Catolicismo romano y forma jurídica (1921) es argumentar que la política en un Estado es la gestión terrenal, a escala humana, de la dialéctica teológica de la muerte-resurrección, lo que en términos políticos se denomina conservación-revolución. En otras palabras, la política en un Estado pretende encontrar "un 'arreglo', [a través de una decisión] entre la sabia nueva (necesaria para romper la costra de lo racional establecido) y lo ya agotado, anquilosado y fosilizado" (Pardo, 2014, p. 26). Es en este juego de muerte y resurrección en que se desarrolla el drama de la historia y se producen las grandes revoluciones.

Los sistemas políticos en Occidente se han configurado como el resultado de decisiones con las que se pretende adecuar la realidad a los órdenes ideales. Los Estados resultantes son abordados por Schmitt a la manera de una genealogía, en $L a$ dictadura: desde los comienzos del pensamiento moderno de la soberanía hasta la lucha de clases proletaria. En este estudio erudito publicado en 1921, Schmitt analiza el desarrollo histórico de 
la forma Estado, desde el Estado de la iglesia en el siglo XV, hasta la Constitución alemana de 1919. Esta última, se ajustó en su momento a un modelo del Estado liberal burgués al cual Schmitt describe críticamente como una organización mecanicista y estéril, que se asemeja a una serpiente que se muerde la cola, pues busca la superación de la brecha entre idea y derecho, a partir de la tramoya del "debate obligante", el cual Schmitt ve materializado en el parlamentarismo ${ }^{7}$.

El reclamo de Schmitt es particularmente relevante si recordamos un texto posterior que tituló Legalidad y legitimidad (1989), dedicado en específico a "caracterizar y atacar la sensibilidad técnico-procedimental de una época cultural (sensu lato) que tiende a reducir y a planear lo político en la administración basada en procedimientos establecidos" (Atilli, 1997, p. 17), pues, por perfecta que sea la técnica, ¿de dónde sacan los Estados liberales la fuerza necesaria para que sus normas penetren la vida, el espíritu y las costumbres del pueblo, tal como una auténtica representación requiere? (Pardo, 2014).

Carl Schmitt afirma que tal tarea es imposible si no se consigue el rescate de una dimensión de la política no reducible, ni agotable, en el mero procedimiento. El filósofo señala que se requiere de un trasfondo moral para las acciones políticas, un telón del cual la decisión sea un fenómeno manifestado. Schmitt quiere ubicar el "alma" que expresa y necesita el poder político "en sus momentos no previstos, ni previsibles" (Atilli, 1997, p. 21), se pregunta concretamente por un poder constituyente, soberano y absoluto.

Una decisión que no sea fenómeno e intento de adecuación de ese absoluto superior, es una decisión sin autoridad. Los Estados liberales son,

Schmitt describe el parlamentarismo como la técnica con la que se pretende otorgar legitimidad y validez a la norma por ser norma, una mecánica de la pura apariencia con la que se ignora de modo deliberado el que la obligatoriedad de una norma o una sentencia se encuentra en la decisión final de ordenar que se cumpla. por ende, Estados sin autoridad y como no hay política sin autoridad, Schmitt infiere con preocupación, que el fin de la política se ha decretado con el advenimiento del Estado liberal burgués. Entonces, ¿cómo puede subsanarse esa era liberal de neutralizaciones? ¿Existe un referente óptimo de forma política capaz de erigirse como "administradora" de la aporía idea-realidad, sin falsearla? Como lo hizo para su definición de decisionismo, Schmitt encuentra en la iglesia católica el referente de una organización que se sostiene por el empleo puro de la autoridad y se ocupa por indagarla filosóficamente.

En Catolicismo romano y forma política, Schmitt explica que al igual que los Estados laicos, la iglesia católica se sostiene sobre una cesura: fe y razón. Sobre ella sus funcionarios operan por la autoridad que les deviene de arriba abajo, sin que con ello reemplacen el lugar del poder absoluto. Para Schmitt, la iglesia católica, como "heredera legítima del viejo derecho romano", ha dejado claro que en su lógica, "la sentencia como forma jurídica por excelencia, decide, pero no [por eso] ocupa el lugar del poder absoluto" (Schmitt, 2011, p. 34).

La autoridad de quienes gestionan el derecho en la iglesia católica no les viene de abajo, ni emana de procedimientos terrenales, no asciende, sino que desciende, es decir, surge de un poder constituyente superior. En consecuencia, en la cesura derecho-poder, la obligatoriedad de la norma proviene de la idea, de tal modo que la autoridad de una decisión, similar a la manera como sucede en el terreno teológico, se sustenta en que la misma, busca darle una dirección al alma humana, sin sacar a la luz la oscuridad irracional que le caracteriza.

La iglesia católica, en el contexto moderno, se convierte para Schmitt en el referente de la forma en que las decisiones pueden sustentarse a partir de la fuerza de un poder constituyente que no asciende, sino que desciende. Para el autor, por tanto, la aplicación de la forma teológica de la decisión a los Estados laicos, es la clave para 
rescatar lo político, del mecanicismo liberal ${ }^{8}$. Celestino Pardo identifica el llamado de Schmitt de la siguiente forma:

Se debe luchar en contra del racionalismo de la ley abstracta y la organización fosilizada del (mal) Estado. Y el único modo de conseguirlo es identificando una fuerza constituyente, renovadora y movilizarla mediante algún mito que permita hacer frente al frío, pero efectivo poder del Estado "abstracto" unilateral, sin vida (2014, p. 25).

Se trata de ubicar el lugar de la deidad como poder constituyente y apelar a él como ley superior.

\section{C. ¿Hitler o Mussolini?: la decisión del decisionista}

La firma del Tratado de Versalles en 1919 tendría un impacto especial en Carl Schmitt, como en todos los pensadores políticos alemanes de la década del veinte. La crisis política y económica influyó en el desarrollo de sus obras; sin embargo, la inestabilidad que vivía Alemania en el ámbito constitucional impactó particularmente la obra del filósofo de Plettenberg, esto se nota en la distancia que tomarían los textos teológico-políticos, frente a las elaboraciones filosófico-ideológicas de esa década. El mejor ejemplo de esta bifurcación en la producción académica de Schmitt, se encuentra en Teología política de 1922 y Catolicismo romano y forma política de 1923, por un lado y La dictadura... (1921) y Sobre el parlamentarismo (1923), por el otro. De la abstracción que caracteriza los dos primeros, se pasa al pragmatismo de los dos últimos textos, en los que el alemán plantea con vehemencia su posición ideológica frente a la República de Weimar.

8 Esta forma es enunciada por Carl Schmitt como la complexio oppositorum, que era la forma representativa de la iglesia romana. Señala Celestino Pardo (2014) que Schmitt se apoya en este modo de representación, pues es el único que puede combinar y poner al servicio de sus fines las más dispares fuerzas materiales e intelectuales.
En los albores de la década del treinta, seis años después de Teología política, la embestida ideológica de Schmitt se define con mayor claridad. La referencia constante a una posible invasión soviética y el crecimiento paulatino del movimiento nacionalsocialista, reflejaba una preocupación especial en Schmitt, en múltiples artículos de prensa, discursos y notas de clase, denuncia la flexibilidad constitucional de la República, que él consideraba, estaba a merced de los enemigos externos soviéticos, e internos del nazismo.

Se dirige explícitamente en contra del artículo 76 de la Constitución de Weimar, el cual fue redactado y en general interpretado de manera que, con una mayoría suficiente en el Parlamento, era posible cualquier reforma constitucional, inclusive aquellas relativas a la identidad misma de la Constitución y del Estado, "convirtiendo una República en una monarquía, un Estado federal en uno centralizado, un Estado con derechos fundamentales, en uno sin esos derechos" (Schlink, 1997, p. 38). Para Schmitt, toda reforma que impactara en la identidad de la Constitución, anula la legalidad y legitimidad de dicha Constitución.

Entre 1926 y 1933 Schmitt hace explícitos sus temores frente a la emergencia de Hitler como figura política, para el filósofo, ese personaje a quien el vulgo llama Führer, no era más que un oradorcillo insulso, el líder de una pandilla de criminales capaces de atentar contra la unidad política básica: el Estado.

¿Estado o movimiento? Esa sería la manzana de la discordia entre Schmitt y el nazismo entre 1926 y 1933, pues mientras que para el último, el movimiento constituía el monopolio de la soberanía y la política, para Schmitt, ese lugar solo podía ocuparlo el Estado. El filósofo de la coacción al orden, veía con recelo el ascenso irresponsable del Partido Nacional Socialista Obrero Alemán frente a la autoridad del Estado. Creía que la prioridad del movimiento frente al Estado, llevaría a Alemania, sin dudas, a la anarquía. Es por esa misma razón que a Schmitt 
le seducía con una infinita superioridad ante el nazismo, el fascismo italiano representado en Benito Mussolini. Pues, ningún orden concreto representaba una garantía real de monopolio de la soberanía por parte del Estado, como lo hacía el fascismo italiano.

Es en el marco de esta discordia, cuando surge El concepto de lo político, en su versión de 1927, el texto sería la respuesta que desde la filosofía política, el constitucionalista alemán pretendía dar a los peligros del nazismo, el liberalismo y el marxismo soviético.

Carl Schmitt se entrevista con Mussolini en febrero de 1926 en el Palazzo di Venezia. A diferencia de Hitler, el líder de las camisas negras era el verdadero héroe de Schmitt. El Schmitt que en alguna ocasión diría: "soy romano por origen, tradición y derecho", consideraba que en el Duce, se encarnaba la sacralización del Estado hegeliano y su propia propuesta teológico-política (Silva-Herzog, 2006).

En su diario, Schmitt describe el encuentro con Mussolini como uno de los momentos más importantes de su vida, le fascinaba la idea de ver cómo podía exacerbarse la defensa del Estado desde la excepción, en una experiencia histórica concreta de la que, además, él era testigo. Schmitt veía en Mussolini, más que al salvador del Estado italiano, al Estado mismo hecho carne:

El abogado quedó cautivado por el dictador. Hablaron de la eternidad del Estado y el carácter efímero del partido. La residencia histórica de Hegel, le dijo Schmitt a Mussolini, está aquí, en Roma. No está en Moscú, ni en Berlín: está aquí en el Palazzo Venezia. Hegel, el sacralizador del Estado, vivía en la musculatura visionaria del dictador de la inmensa quijada. Aquella conversación permanecería en la memoria de Schmitt como uno de los momentos de mayor placer intelectual en su vida, un encuentro inolvidable en cada uno de sus detalles (Silva-Herzog, 2006, p. 20).
Esta fascinación influiría en la producción teórica del alemán, la realidad de su tiempo exigía una noción de vida pública que no se contemplaba en su teología política, era necesario para Schmitt, un elemento pragmático que describiera, más allá del origen de la política, una política del origen. Es decir, una explicación filosófica sobre cómo se hace la política y qué es la política; si Alemania le preguntaba, Italia le respondía. La experiencia protofascista de la marcha de las camisas negras sobre Roma, influiría notablemente en Schmitt. Para él, la jornada de octubre de 1922 representaba:

Un potente movimiento que, al mismo tiempo que salvaba a la burguesía de la amenaza comunista, lanzaba al Estado a la conquista del futuro. Ahí se abría la puerta de la historia por venir; el fascismo contenía una nueva retórica, una nueva estética. En la marcha de los fascistas se desplegaba escénicamente el poder de la masa, la chispa motriz de un Estado original. Mussolini es el arrojo: el diputado violento a quien pocos toman en serio, hace llamados al rey para imponer el orden. Nada sucede. Entonces, tras el silencio de la tradición, inunda las calles de camisas negras y asume el control del Estado. Tras mostrar su poder, lo conquista. El viejo Estado, como un monumento de arena, se desmorona en un soplo (citado en Silva-Herzog, 2010, p. 23).

Influido por esta simpatía, el filósofo escribe en 1927 El concepto de lo político, en este ensayo ofrece, en virtud de un Estado que se refunda desde la excepción, una explicación a la pregunta: ¿qué es la política? Carl Schmitt esboza lo que a su juicio es la vida pública y lo hace en los términos de una lucha por el control del Estado. Es difícil no pensar que Schmitt tiene en mente la experiencia italiana, máxime cuando, simultáneamente, expresa por diferentes medios su repudio al nazismo, el liberalismo y el marxismo soviético.

Si Mussolini despertaba admiración en Schmitt, Hitler era el dueño de su aversión. El biógrafo Silva-Herzog sintetiza bien lo que representaba el 
uno para el otro: "El primero sentía una mezcla de desprecio y fascinación por el dictador; el segundo jamás dio importancia al hombre que se ofreció para razonar sus atropellos"9.

En efecto, hasta un día antes del triunfo electoral del nazi, Carl Schmitt manifiesta en la prensa berlinesa que "quien colabora con los nazis está actuando tonta e irresponsablemente" (citado en Silva-Herzog, 2006, p. 13) advertía a los alemanes, ebrios del discurso del Führer, que "El nacionalsocialismo era un movimiento peligroso que podía cambiar la Constitución, establecer una iglesia de Estado, disolver los sindicatos y aplastar los derechos" (citado en Silva-Herzog, 2006, p. 14). En sus clases en la Universidad de Colonia, dejaba ver que a pesar de ser el representante de "ideas que contrariaban el imperio estricto de la ley, nunca desearía el fracaso del orden institucional" (citado en Silva-Herzog, 2006, p. 14) por esa razón, decía a sus estudiantes, no apoyaba el ascenso de los nazis al poder.

Esta sensación acompañaría a Schmitt incluso después del triunfo de Hitler en las urnas. El 7 de abril de 1933, Schmitt registra lo que representó su primer y único encuentro con el dictador. En el Glossarium: Aufzeichnungen der Jahre 1947-51 (Schmitt, 1991), Hitler aparece como un hombre inseguro que depende obsesivamente de las reacciones de su auditorio. Diría explícitamente, que: "Como un enfermo, el orador necesitaba del respirador del aplauso. Todo el mundo lo escuchaba $0 . .$. y nada. Visto de cerca, el gran agitador de las masas era un oradorcillo insulso" (Schmitt, 1991, p. 255). Describe la llegada de Hitler al recinto como la entrada de un toro asustado ante los rostros inmóviles de los jerarcas del partido. Nada en ese hombre se asemejaba al soberano que había descrito en Teología política. Unas semanas después de su encuentro, más por oportunismo que por cualquier otra razón, Schmitt se vincula al Partido Nazi.

9 Habría que matizar, frente a la precepción de Schmitt, que el desprecio iría primero que la fascinación y que ese sentimiento, por más que intentó ocultarlo, nunca le abandonaría.

\section{Oportunismo y desesperación: de conservador a antisemita}

Hay que recordar que Carl Schmitt se afilia al nazismo por invitación de Heidegger. No obstante, hasta ese momento Schmitt, pertenecía al Movimiento Revolucionario Conservador que reunía a Oswald Spengler, Arthur Moeller van den Bruck, Ludwig Klages, Ernst Niekisch, y a su amigo Ernst von Salomon Jünger, una facción burguesa, católica y conservadora de la juventud alemana. Después de la elección de Hitler, los conservadores alemanes fueron vigilados por las SS, lo que les obligó, exceptuando a Jünger y Schmitt a huir de Alemania. Antes de eso, Ernst Niekisch, su amigo periodista, había sido enviado a un campo de concentración como retaliación por la publicación de Hitler, una fatalidad alemana en $1932^{10}$.

Por su parte y a finales de 1933, Schmitt opta por mantenerse en Alemania y reedita El concepto de lo político, eliminando toda referencia al marxismo e incluyendo tesis antisemitas; además de reemplazar el término "Estado" por el de "movimiento" en lugares cruciales de su argumentación; y de llamar a Hitler "arquitecto de la nueva legalidad"11. Desde entonces, los esfuerzos de Schmitt por simpatizar con el régimen darían frutos; ahora la prensa del partido lo llama "abogado de la Corona" y "alfil del Tercer Reich", Hitler le hizo miembro del Consejo de Estado y ante el exilio de Hans Kelsen, pasa a ocupar el estatus del más distinguido catedrático de la Facultad de Leyes de la Universidad Libre de Berlín ${ }^{12}$.

10 Al respecto véase Ríos (2014). Bernd Rüthers, relata que "cuando el Kölnische Zeitung (Diario de Colonia) señaló en un artículo a Höhn como discípulo de Schmitt, protestó enérgicamente en una carta contra 'falsa afirmación' y recalcó que nunca había sido estudiante [de] Schmitt y estaba distanciado de sus opiniones" (Rüthers, 2004, p. 97).

11 El texto se encuentra en español con el título El Führer defiende el derecho en la compilación de Héctor Orestes Aguilar (2001).

12 Cabe recordar que Hans Kelsen había apoyado a Schmitt para vincularse a la Universidad de Colonia, a pesar de sus diferencias. Durante el nazismo, Kelsen fue expulsado de la universidad mientras estaba de 
Pero los fundamentos con los que explica el origen de la soberanía, completamente aparte de la cuestión racial, el valor del Estado sobre el movimiento y sus metáforas alusivas al catolicismo en Teología política, hacen que desde 1934 Schmitt empezara a recibir fuertes críticas por parte del nazismo. Las razones: su confeso catolicismo y sobre todo, por su posición ambivalente frente a la primacía del partido sobre el Estado.

Dos años más tarde, Schmitt es investigado y atacado por las SS, especialmente por Otto Ohlendorf su secretario mayor ${ }^{13} \mathrm{y}$ por el director del departamento de la Oficina Central de Seguridad del Reich, Reinhard Höhn ${ }^{14}$ (Rüthers, 2004), quien lo acusaba de atentar contra el Movimiento con un discurso que califica de "Absolutista de Estado".

vacaciones en Suecia. Los docentes de la Facultad de Derecho se reunieron para solicitar la reinstalación del profesor Kelsen. El único académico que se opuso fue Carl Schmitt.

13 Tres años después Ohlendorf sería nombrado por Heinrich Himmler como secretario general de la Oficina Central de Seguridad del Reich (RSHA o Reichssicherheitshauptamt), departamento que resultó de la fusión de la Oficina Central de Seguridad del Reich, la Gestapo (policía secreta del Estado) y la Kripo (policía criminal). Finalmente en 1941, luego de una larga carrera investigando y capturando a los enemigos políticos del Reich, Ohlendorf alcanza el grado de general de División de las SS y llega a ser secretario de Estado de Economía.

14 Höhn fue el más poderoso enemigo de Schmitt. También era abogado de derecho público y competía con Schmitt, desde antes del ascenso del nazismo, por lograr un lugar como profesor titular en la Universidad Libre de Berlín. A diferencia de Schmitt, Höhn hizo gala pública de su antisemitismo en el periodo de entreguerras, al ser un miembro destacado de la orden de la juventud alemana. Höhn formó parte del llamado brain trust, un grupo de jóvenes académicos tecnócratas que había convocado $R$. Heydrich, la mano derecha de Himmler, para controlar los cargos de alta burocracia nazi. El biógrafo Bernd Rüthers presenta evidencia histórica que demuestra que Reinhard Höhn vigiló el correo, las actividades profesionales, políticas y los contactos personales de Carl Schmitt durante el verano de 1936. Rüthers, relata que "cuando el Kölnische Zeitung (Diario de Colonia) señaló en un artículo a Reinhard Höhn como discípulo de Schmitt, este protestó enérgicamente en una carta contra 'falsa afirmación' y recalcó que nunca había sido estudiante [de] Schmitt y estaba distanciado de sus opiniones" (2004, p. 97).
Desesperado por recuperar la atención positiva de los jerarcas del partido, en octubre de 1936 Schmitt propone la realización del Congreso "La judería en la ciencia jurídica alemana" de la mano de la Asociación de Guardianes del Derecho Nacionalsocialista, en Berlín. Schmitt celebra el evento con el objetivo de inspirar a la lucha de la ciencia jurídica alemana contra el espíritu judío (Rüthers, 2004), y además para limpiar su nombre ante los nazis.

Al encuentro asisten unas cuatrocientas personas, ante quienes Schmitt propone la creación de un sistema de referenciación antisemita, conocido como la "Estrella Literaria", pues, como lo expresó en el discurso de cierre, después de un congreso de esa magnitud, "ya no es posible citar a un autor judío, como a cualquier otro autor" (citado en Rüthers, 2004, p. 110); debe ser designado con una estrella de David seguido de su apellido o "con la simple mención de la palabra jüdisch, [para generar] un exorcismo saludable" (citado en Rüthers, 2004, p. 110).

Sus esfuerzos fueron en vano. En el periódico interno de las SS, Das Schwarze Korps, es acusado de mentiroso y oportunista. Se describe el Congreso como un intento por "encubrir sus antiguas amistades con judíos" (Rüthers, 2004, p. 114), Höhn, quien consideraba a Schmitt un "obstáculo en sus planes de carrera le califica como un sospechoso oportunista" (Rüthers, 2004 pp. 96-103) y revela la correspondencia que mantenía con sus antiguos compañeros del conservadurismo burgués.

A fines de 1936, Carl Schmitt se ve obligado a renunciar a los privilegios del partido. Como lo afirma Rüthers (2004), finalmente, "Schmitt no se distanció en 1936 y 1937 del nacionalsocialismo. Ocurrió lo contrario: una importante y poderosa parte del aparato de poder nazi se apartó de él" (p. 117), sus esfuerzos por mantenerse en la práctica cercano al nazismo, fracasaron por la distancia original e insalvable que sus teorías sobre el origen del derecho y el poder representaban, frente a los fundamentos del nazismo. 


\section{Conclusión}

El decisionismo de Schmitt permite explicar que el gobierno de la ley depende en última instancia de un acto abismal de violencia, es decir, que en la distancia entre idea y realidad existe la mediación-inmediata de imposición de un acto de decisión. Esto no significa que Schmitt comulgue con una visión apocalíptica del Estado; todo lo contrario: aunque se sale del formalismo democrático liberal, su comprensión de la política es ante todo una justificación conservadora de la existencia del Estado moderno, lo que constituye un elemento claramente contrario a las pretensiones revolucionarias del nazismo.

Para este Schmitt decisionista, el Estado es el centro fijo de toda su argumentación filosófica. Aunque la decisión soberana preceda al Estado, existe una tendencia natural al orden que gobierna sobre la misma decisión, de tal modo que esta siempre se orienta hacia la preservación del Estado como forma política genérica. En otras palabras, la brecha entre idea y realidad queda, para Schmitt, en un plano de "abstracción relativa", puesto que la decisión a la que se refiere, como mediadora in-mediata, está siempre desprovista de algún contenido concreto $y$, sin embargo, se orienta en todo caso hacia la reafirmación del orden como principio fundamental. Esto que podemos llamar "tendencia al orden", sale a flote en pocas ocasiones en esta primera faceta de Schmitt con el nombre de "principio de coacción al orden" (Schmitt, 2011).

La implícita propensión al orden en toda decisión soberana es el rasgo que define la tendencia conservadora de Carl Schmitt dado que, aunque el contenido concreto de la decisión sea arbitrario y dependiente de la voluntad del soberano y de la contingencia histórica y no se sepa realmente cómo el soberano orientará al Estado ante una situación excepcional (puede elegir una monarquía o una democracia, un Estado centralista o uno federal), lo único cierto es que sobre tal decisión gobierna el principio-del-orden-en-sí, que Carl Schmitt denominó principio de coacción al orden.
Por esto Schmitt es un verdadero moderno, pues aun cuando elije un camino distinto y contrario al del liberalismo, justifica la existencia del orden burgués amparándose en su idea de decisión infundada, y al hacerlo, halla los argumentos sólidos e irrefutables de los cuales carecen sus antagonistas liberales ${ }^{15}$. A pesar de que el final sea el mismo: la defensa de la modernidad burguesa, la vía que escoge Schmitt le diferencia del liberalismo, en la medida en que explica, con la contundencia de lo imperfecto y lo indiscutible, la existencia del Estado moderno, el cual, desde el decisionismo schmittiano, se justifica en el hecho de no tener necesidad de ninguna "justificación" racional.

De acuerdo con ello, la propuesta de este Schmitt, teólogo de la política, es ante todo la de un "modernismo conservador" que se sostiene sobre una situación trágica: la única manera de que exista la modernidad es con el "regreso de una autoridad incondicional que no puede [o no necesita] fundamentarse en razones positivas" (Žižek, 2011, p. 46). Este es el sentido de su teología política y su apuesta como un filósofo conservador.

En conclusión, esta primera etapa de Carl Schmitt nos deja a un crítico del racionalismo burgués liberal y a un defensor del Estado como forma política de la modernidad. Para este Schmitt, la dicotomía normalidad/excepción es la base para la comprensión de la política, en tanto que da lugar a la soberanía. La excepción puede ser sucedida por múltiples órdenes concretos, de ahí su famosa frase: "Todos los Estados son Estados de derecho"16. Esto implica que Schmitt es un universalista que no se detiene a definir qué orden concreto favorece el ejercicio de la soberanía, cómo emerge el soberano en una situación excepcional, ni cuáles son las características de ese momento hipotético preestatal y prejurídico

15 Una interpretación similar se encuentra en Žižek (2011).

16 Lo que no se debe confundir con una simpatía por Kelsen, por el contrario, es una fuerte crítica, ya que supone que la dictadura, la monarquía y la democracia liberal son Estado de derecho en la medida en que, como órdenes, se soportan jurídicamente. 
del que surgen las decisiones soberanas, es decir, es un filósofo que echa por tierra al partido y al movimiento, y cualquier otra unidad política, ante la omnipotencia del Estado.

Desde luego, las cosas cambiaron para el pensador alemán a partir del 30 de enero de 1933; la convulsionada década del treinta del siglo XX "llenará de contenido" lo que hasta el momento habían sido abstracciones muy elaboradas sobre el origen del derecho, el Estado y la modernidad.

Se puede objetar con evidencia histórica y casi desde cualquier perspectiva, lo aquí planteado, pues ciertamente, Carl Schmitt nunca dimitió públicamente del nazismo, y es fácil, como lo hace Charles Yves Zarka (2007), hallar pruebas o "detalles nazis" en su vida y obra ${ }^{17}$. Sin embargo (más allá de los detalles), el conjunto de su obra, desde sus génesis, hace que la afirmación "Carl Schmitt... el filósofo nazi", asuma matices que relativizan la cuestión. Eso es lo que hemos pretendido demostrar en este artículo.

¿Qué tanta convicción y qué tanto oportunismo habría en la decisión de Schmitt de afiliarse al Partido Nazi? Esa es una pregunta propia para sus biógrafos; en lo que aquí concierne, desde la perspectiva filosófica, es posible concluir que aun desde su origen, el pensamiento schmittiano está signado por una interpretación de la política próxima al conservadurismo católico burgués, lo que fue, lejos de una simpatía para el Führer (al lado del judaísmo y el marxismo) uno de los más importantes enemigos ideológicos del régimen nazi.

\section{Referencias}

Atilli, A. (1997). Prefacio. En: C. Schmitt (autor). El Leviatán en la doctrina del Estado de Thomas Hobbes. México D. F.: Biblioteca de Ética y Filosofía del Derecho y Política.

17 A propósito de la investigación Un detalle nazi en el pensamiento de Carl Schmitt de Zarka (2007).
Córdova, V. L. (2013). Derecho y poder: Kelsen y Schmitt frente a frente. México D. F.: Fondo de Cultura Económica.

D’ors, A. (2002). El Glossarium de Carl Schmitt. En: Estudios sobre Carl Schmitt. Madrid: Paidós.

Fioravanti, M. (1994). Stato e Costituzione. Turín: Padua.

Heller, A. (2006). Prólogo. En: C. Schmitt (autor). El Leviatán en la doctrina del Estado de Thomas Hobbes. México D. F.: Biblioteca de Ética y Filosofía del Derecho y Política.

Kahn, P. W. (2012). Teología política: cuatro nuevos capítulos sobre el concepto de soberanía. Bogotá: Nuevo Criterio Jurídico, Universidad de los Andes, Instituto Pensar.

Lübbe, H. (1983). Filosofía práctica y teoría de la historia. Barcelona: Alfa.

Orestes, A. H. (2001). Carl Schmitt, teólogo de la política. México D. F.: Fondo de Cultura Económica.

Pardo, C. (2014). Edición, estudio introductorio y traducción. En: C. Schmitt (autor). El valor del Estado y el significado del individuo. Madrid: Centro de Estudios Políticos y Constitucionales, Ministerio de la Presidencia.

Ríos, R. H. (2014). La República fascista de las letras. Disponible en: http://www.perfil.com/ cultura/Doble-Moral-20140208-0093.html

Rüthers, B. (2004). Carl Schmitt en el tercer Reich. Serie de Teoría Jurídica y Filosofía del Derecho, 32. Bogotá: Universidad Externado de Colombia.

Schmitt, C. (1931). El guardián de la Constitución. Madrid: Trotta.Schmitt, C. (1968). La dictadura. Desde los comienzos del pensamiento moderno de la soberanía hasta la lucha de clases proletaria. Madrid: UCM.

Schmitt, C. (1989). Legalidad y legitimidad. Buenos Aires: Struhart \& Cía. 
Schmitt, C. (1991a). El concepto de lo político. Madrid: Alianza Editorial.

Schmitt, C. (1991b). Glossarium: Aufzeichnungen der Jahre 1947-51. Múnich: Duncker \& Humblot.

Schmitt, C. (1998). Teología política. Buenos Aires: Struhart \& Cía.

Schmitt, C. (2006). El Leviatán en la doctrina del Estado de Thomas Hobbes. México D. F.: Biblioteca de Ética y Filosofía del Derecho y Política.

Schmitt, C. (2011). Catolicismo romano y forma política. Madrid: Tecnos.

Schmitt, C. (2012). Teoría de la Constitución. Madrid: Alianza Editorial.

Schmitt, C. (2013). Teoría del partisano: acotación al concepto político. Madrid: Trotta.

Schmitt, C. (2014). El valor del Estado y el significado del individuo ( $1^{\text {a }}$ ed., $1^{\text {a }}$ reimp.). Madrid: Centro de Estudios Políticos y Constitucionales, Colección Clásicos Políticos.

Schlink, B. (1997). ¿Por qué Carl Schmitt? Revista Precedente Jurídico, 20.

Silva-Herzog, J. (2006). La idiotez de lo perfecto. Miradas a la política. México D. F.: Fondo de Cultura Económica.

Villacañas, J. L. (2013). En diálogo con Weber. Sobre la tiranía de los valores de Carl Schmitt. Co-herencia, 10(18), enero-junio, pp. 13-40.

Weber, M. (1979). El político y el científico. Madrid: Alianza Editorial.

Zarka, C. Y0. (2007). Un detalle nazi en el pensamiento de Carl Schmitt. Barcelona: Anthropos.

Žižek, S. (2011). Carl Schmitt en la era de la post-política. En: C. Mouffe (comp.). El desafío de Carl Schmitt. Buenos Aires: Prometeo. 